\title{
Feedback ter bevordering van de professionele ontwikkeling van docenten
}

\author{
D.H.J.M. Dolmans, R.E. Stalmeijer, H.A.P. Wolfhagen
}

\begin{abstract}
Samenvatting
Feedback aan docenten wordt verondersteld de professionele ontwikkeling van de docent te stimuleren. Belangrijke voorwaarden zijn dat de feedback specifiek, diagnostisch en relevant is en suggesties voor verbetering bevat. Bij voorkeur vindt de feedback niet alleen schriftelijk plaats, maar wordt de docent geholpen bij het interpreteren van de feedback en vindt er dialoog en discussie plaats over de feedback. Voor het geven van feedback wordt steeds meer gebruik gemaakt van verschillende instrumenten en verschillende informatiebronnen. Deze informatie kan opgenomen worden in een docentportfolio waarin de docent reflecteert op de bewijsstukken en zichzelf doelen stelt voor zijn of haar professionele ontwikkeling. (Dolmans DHJM, Stalmeijer RE, Wolfhagen HAP. Feedback ter bevordering van de professionele ontwikkeling van docenten. Tijdschrift voor Medisch Onderwijs 2006;25(6):267-272.)
\end{abstract}

\section{Inleiding}

In de huidige nieuwe onderwijsvormen ligt de nadruk op actief, betekenisgericht, toepassingsgericht, zelfstandig en samenwerkend leren van studenten. Deze vormen zouden ervoor moeten zorgen dat kennis beter beklijft, beter wordt begrepen en beter toegepast kan worden. Deze nieuwe onderwijsvormen zouden bovendien beter voorbereiden op een leven lang leren. ${ }^{1} \mathrm{Ze}$ stellen ook andere eisen aan docenten. De docent moet niet alleen goed kunnen uitleggen of informatie kunnen overdragen, maar moet goede feedback kunnen geven, kunnen coachen, kunnen begeleiden tijdens praktijkleren, et cetera. Om docenten goed voor te bereiden op de eisen die deze nieuwe onderwijsvormen stellen, wordt er tegenwoordig steeds meer aandacht besteed aan het opleiden en scholen van docenten. Vele medische centra bieden allerlei cursussen aan voor docenten op het gebied van werkplekbegeleiding, het toetsen van studenten, et cetera. Ook is er een toenemende belangstelling voor het evalueren van docenten. Verondersteld wordt dat evalueren en feedback aanzetten tot reflectie en de professionele ontwikkeling van de docent stimuleren. Dit zou ten goede komen aan de kwaliteit van het onderwijs en uiteindelijk het leren van studenten. Evaluatie en feedback vormen de kern van elke poging om het onderwijzen en leren van docenten te verbeteren. ${ }^{2}$ In dit artikel wordt uiteen gezet onder welke voorwaarden feedback aan docenten effectief is. Ook wordt aandacht besteed aan de verschillende instrumenten die gebruikt kunnen worden om docenten van feedback te voorzien.

\section{Voorwaarden voor effectieve feed- back \\ Feedback moet in eerste instantie ge- richt zijn op verbetering}

Feedback moet vooral bedoeld zijn om docenten aan te zetten tot reflecteren over de wijze waarop ze doceren en een bijdrage leveren aan het verbeteren van hun docentcompetenties. Uit onderzoek blijkt dat feedback meestal een positief effect heeft op het functioneren van iemand, maar niet altijd. ${ }^{3}$ Dit is bijvoorbeeld afhankelijk van de mate waarin een persoon 
de betreffende competentie wil verbeteren. Ook is bekend dat extreem negatieve feedback meestal niet tot verbetering leidt en zelfs een averechts effect kan hebben.

Veel onderwijsorganisaties starten met het implementeren van evaluatiesystemen om docenten van feedback te voorzien. De feedback heeft in eerste instantie vooral een formatieve functie en is bedoeld om de competenties van de docent te verbeteren. Vaak wordt de feedback later ook betrokken bij het nemen van beslissingen, bijvoorbeeld bij bevorderingen of benoemingen. De feedback heeft dan een summatieve functie. De nadruk dient echter ook dan te blijven liggen op het geven van feedback om van te leren. ${ }^{4}$ Het leren van de docent en het verbeteren van zijn of haar professionele ontwikkeling dient met het oog op kwaliteitsverbetering van het onderwijs immers centraal te staan.

Een nadeel van het gebruik van feedback voor besluitvorming of summatieve doelen is dat iemand die negatieve feedback krijgt zich bedreigd kan voelen. Dit kan er toe leiden dat de docent gaat proberen een positieve indruk achter te laten in plaats van zijn functioneren te verbeteren. ${ }^{3}$ Een voordeel van het gebruik van feedback voor het nemen van beslissingen of het afleggen van verantwoording is dat de docent de evaluaties serieus neemt. Het is echter vaak goed mogelijk de formatieve en summatieve functie te combineren. ${ }^{4}$ Antwoorden op open vragen, bijvoorbeeld vragen over de sterktes en verbeterpunten, kan de docent gebruiken om van te leren, terwijl globale cijfers over het functioneren van de docent in verschillende onderwijsrollen, verkregen met hetzelfde instrument, betrokken kunnen worden bij beslissingen over bevorderingen.

\section{Feedback is bij voorkeur gebaseerd op verschillende informatiebronnen}

Er zijn meerdere perspectieven mogelijk op wat goed onderwijs is en ook op wat een goede docent is. Dit betekent dat bij het evalueren en het geven van feedback ruimte moet zijn voor verschillende interpretaties. ${ }^{4}$ Dit kan bereikt worden door verschillende informatiebronnen bij de feedback te betrekken die vanuit verschillende perspectieven naar de docent kijken. Te denken valt aan de docent zelf, studenten, collega-docenten, werkbazen, directeuren van onderwijsinstituten, onderwijskundigen of andere experts.

\section{Feedback moet specifiek, diagnostisch en relevant zijn en suggesties voor ver- betering bevatten}

Braskamp en Ory geven verschillende suggesties voor het bevorderen van het gebruik van feedback door docenten. ${ }^{5}$ Een van hun suggesties is specifieke, diagnostische en beschrijvende feedback te geven in plaats van alleen een globaal oordeel. DeNisi en Kluger geven aan dat feedback effectiever is als deze gericht is op het verbeteren van de competenties van de docent en niet op de persoon of op het zelfbeeld van een persoon. Feedback is ook effectiever als de feedback informatie bevat over hoe het functioneren verbeterd kan worden en als er over de feedback gediscussieerd kan worden. ${ }^{3}$ In een recente meta-analyse over feedback wordt geconcludeerd dat positieve feedback sneller geaccepteerd wordt dan negatieve feedback, dat negatieve feedback ontmoedigend kan werken en dat feedback eerder effect heeft indien er een behoefte bestaat aan verandering. 6 Sargeant maakt een onderscheid tussen feedback over de inhoud en het proces. Feedback op de inhoud moet duidelijk, specifiek, relevant en wederzijds begrijpbaar zijn. Voor feedback op het proces zijn de volgende criteria van be- 
lang: op tijd, interactief en niet oordelend, voorzien van uitleg, rekening houdend met de gevoelens en het perspectief van de ontvanger, en bovendien moet feedback suggesties bevatten voor verbetering. ${ }^{7}$

\section{Help docenten bij het interpreteren van de feedback}

Braskamp en Ory beargumenteren dat discussie en dialoog over de feedback behulpzaam is voor docenten voor het verkrijgen van suggesties voor alternatief gedrag. ${ }^{5}$ Indien docenten kunnen discussiëren over de feedback, wordt verwacht dat deze feedback meer effect heeft dan indien de feedback alleen schriftelijk wordt verstrekt. Ook DeNisi en Kluger wijzen erop dat feedback effectiever is als er discussie over de feedback plaatsvindt. ${ }^{3}$ Docenten moeten dan ook gestimuleerd worden kritisch te reflecteren op de feedback die zij ontvangen. Uit onderzoek naar het gebruik van docentportfolio's bij docenten blijkt dat dialoog en interactie, naar de mening van de betrokken docenten, van groot belang zijn voor de bijdrage die een docentportfolio kan leveren aan de professionele ontwikkeling van de docent. Deze dialoog kan groepsgewijs georganiseerd worden, waarbij docenten van elkaar leren, bijvoorbeeld tijdens intervisiebijeenkomsten. Het is ook mogelijk om een persoonlijke coach te koppelen aan een docent. ${ }^{8}$

\section{Instrumenten voor het geven van feedback aan docenten}

Voor het geven van feedback aan docenten kunnen verschillende instrumenten gebruikt worden, zoals vragenlijsten, observaties en portfolio's. Daarnaast kunnen verschillende informatiebronnen betrokken worden bij het geven van feedback, zoals studenten (studentevaluaties), docenten zelf (zelfevaluaties) of collega-do- centen (peer feedback) die vanuit verschillende perspectieven naar het functioneren van een docent kijken.

\section{Vragenlijsten}

Vragenlijsten die gebruikt worden om het functioneren van docenten te evalueren bestaan veelal uit gesloten vragen in de vorm van beweringen en enkele open vragen. Gesloten vragen zijn relatief gezien makkelijker te analyseren dan open vragen. De constructie van gesloten vragen is echter niet eenvoudig. Om een docent in een bepaalde onderwijsrol te evalueren, zal eerst nagedacht moeten worden over de vraag welke factoren de effectiviteit van de docent beïnvloeden. Bij voorkeur wordt hierbij gebruik gemaakt van theorieën over effectief onderwijzen. Voor het functioneren van de tutor in een probleemgestuurd curriculum kan bijvoorbeeld gebruik gemaakt worden van theorieën over effectief leren, zoals actief leren, zelfgestuurd leren, toepassingsgericht leren en samenwerkend leren (zie bijvoorbeeld: Dolmans en Ginns; 9 Dolmans DHJM, Wolfhagen HAP, Snellen-Balendong HAM, Heus GCB de ${ }^{10}$ ). Tot nu toe werd vooral in de bachelorfase van de geneeskundeopleiding veel gebruik gemaakt van vragenlijsten om de docent van feedback te voorzien. Er is echter steeds meer aandacht voor het geven van feedback aan docenten tijdens de masterfase waarin het praktijkleren centraal staat. Te denken valt hierbij aan instrumenten waarmee de kwaliteit van de begeleiding die de docent biedt gedurende het praktijkleren gemeten kan worden (zie bijvoorbeeld: Copeland en Hewson; ${ }^{11}$ Dolmans, Wolfhagen, Gerver en Scherpbier; ${ }^{12}$ Litzelman, Stratos, Marriott en Skeff; ${ }^{13}$ Van der Hem-Stokroos, Van der Vleuten, Daelmans, Haarman en Scherpbier ${ }^{14}$ ). Bij de keuze van een instrument is het van belang na te gaan of de vragen zijn geba- 
seerd op theorieën over effectief onderwijzen en of de vragenlijst getest is op betrouwbaarheid en validiteit.

Indien vragenlijsten gebruikt worden voor het geven van feedback, dan worden deze meestal ingevuld door studenten. Studenten vormen een belangrijke bron van informatie over het functioneren van docenten, aangezien zij het onderwijs consumeren. Uit onderzoek is gebleken dat studentoordelen betrouwbaar en valide zijn en nauwelijks beïnvloed worden door ongewenste effecten zoals milde beoordelingen van studenten door docenten. ${ }^{15}$ Maar, om een betrouwbaar oordeel te kunnen geven over het functioneren van een docent, is een voldoende aantal studentoordelen nodig. Uit onderzoek naar het functioneren van tutoren in probleemgestuurde onderwijsgroepen van tien studenten is bijvoorbeeld gebleken dat tenminste zes studentoordelen nodig zijn. ${ }^{9}$ Het is van belang om hier rekening mee te houden, zeker indien het oordeel ook gebruikt wordt om beslissingen over docenten te nemen. Vragenlijsten kunnen echter ook ingevuld worden door collegadocenten, de docent zelf of andere experts. Hier bestaat steeds meer belangstelling voor.

\section{Observaties}

Het is ook mogelijk een observatieinstrument te ontwikkelen om het functioneren van de docent te meten. Observaties vinden plaats in een authentieke situatie en bieden ruime mogelijkheden voor het geven van feedback. Observaties zijn echter tijdsintensief en vaak niet betrouwbaar en valide. Observaties vereisen training van de observatoren. ${ }^{16}$ Ook is het nodig globale richtlijnen te formuleren voor de observatoren over de aspecten die geobserveerd worden en zijn er bij voorkeur meerdere observatoren betrokken. Observaties kunnen plaatsvinden door de docent zelf, bijvoorbeeld door deze een video te laten bekijken, door studenten die hiervoor een training hebben gehad, door collega-docenten of door een onderwijskundige of andere expert.

\section{Docentportfolio's}

Tegenwoordig maken steeds meer opleidingen gebruik van docentportfolio's. Een docentportfolio is een verzamelmap waarin allerlei bewijsmaterialen zitten die een beeld geven van het functioneren van een docent. Die bewijsmaterialen kunnen studentevaluaties zijn, resultaten van observaties, maar ook materialen die de docent ontwikkeld heeft, bijvoorbeeld een cursus of een toets. De bewijsmaterialen kunnen bestaan uit zelf-evaluaties of peerevaluaties ofwel evaluaties door collegadocenten. Tegenwoordig wordt vaak gesproken over multi-source feedback of 360 graden feedback. Bij multi-source feedback geven verschillende informatiebronnen feedback aan de docent, zoals studenten, de docent zelf, een collega-docent, een onderwijskundige. Multi-source feedback werd vooral in het bedrijfsleven toegepast, maar wordt ook steeds meer gehanteerd in het onderwijs en dan vooral voor het geven van feedback op iemands functioneren in praktijksituaties. ${ }^{17}$ De gegevens die verkregen zijn uit multi-source feedback kunnen opgenomen worden in het portfolio, evenals zelfevaluaties. Seldin beargumenteert dat het zinvol is om docenten te vragen hetzelfde evaluatieformulier in te vullen als hun studenten en hen achteraf te vragen de resultaten te vergelijken. Deze zelfevaluaties en mogelijke discrepanties met de evaluatie van de studenten zullen de docent stimuleren te reflecteren op zijn of haar functioneren. ${ }^{16}$

Een portfolio dat bedoeld is om de professionele ontwikkeling van de docent te stimuleren, is echter meer dan een ver- 
zamelmap met materialen. Het bevat ook een onderdeel waarin de docent reflecteert op de bewijsstukken en waarin de docent aangeeft welke doelen deze zich heeft gesteld voor zijn of haar professionele ontwikkeling. Bovendien laat de docent in een portfolio zien op welke wijze er gewerkt is aan de gestelde doelen en of dit resulteerde in verbetering van zijn of haar docentcompetenties. Bij voorkeur bevat het portfolio enige structurering, maar deze is niet te gedetailleerd en te directief, zodat er ruimte blijft voor individuele invulling. ${ }^{4}$ Een voordeel van het gebruik van een docentportfolio is dat de docent zelf sterk betrokken is en een grote verantwoordelijkheid krijgt bij de evaluatie. De docent selecteert immers zelf de materialen, reflecteert daarop en formuleert verbeterdoelen, wat het leren van de docent bevordert.

In sommige opleidingen wordt geëxperimenteerd met het gebruik van docentportfolio's voor het nemen van beslissingen, bijvoorbeeld bij het bevorderen van docenten. Aangezien een portfolio een rijke hoeveelheid aan veelal kwalitatieve materialen bevat is het niet gemakkelijk een portfolio te beoordelen. Door Tigelaar, Dolmans, Wolfhagen en Van der Vleuten is voorgesteld om bij de beoordeling van docentportfolio's criteria te hanteren die ook gebruikt worden bij kwalitatief onderzoek. Te denken valt aan de volgende criteria: betrek beoordelaars vanuit verschillende perspectieven bij de beoordeling en laat hen discussiëren over hun interpretaties en die herzien, documenteer de stappen in het beoordelingsproces en betrek de docent zelf ook bij de beoordeling. ${ }^{18}$

\section{Conclusie}

Voor het evalueren en geven van feedback aan docenten werd vroeger vooral gebruik gemaakt van studentevaluaties. Tegenwoordig wordt er steeds meer gebruik ge- maakt van verschillende meetinstrumenten en verschillende informatiebronnen. Er zijn immers meerdere perspectieven mogelijk op wat goed onderwijs en wat een goede docent is. De verschillende evaluaties kunnen samengevoegd worden in een docentportfolio waarin de docent reflecteert op de evaluaties en verbeterdoelen formuleert. Door gebruik te maken van verschillende instrumenten en verschillende informatiebronnen is het beter mogelijk een compleet beeld te krijgen van de competenties van de docent dan door gebruik te maken van één instrument of één informatiebron.

Tegenwoordig ligt er bij het geven van feedback ook meer nadruk op het leren van de docent. Om te zorgen dat feedback aan docenten leidt tot verbetering van de docentcompetenties, wordt steeds meer aandacht besteed aan het organiseren van dialoog rondom evaluaties. Dialoog en discussie met de docent over de feedback zetten de docent aan tot reflecteren over zijn of haar docentcompetenties. De verwachting is dat deze reflecties resulteren in veranderde opvattingen van de docent over hoe effectief leren van studenten bevorderd kan worden en in een verbetering van de competenties van de docent. Er is echter veel meer onderzoek nodig naar hoe docenten zich optimaal kunnen professionaliseren en wat feedback en reflectie daaraan kunnen bijdragen. Ook is het nodig te onderzoeken of de positieve effecten van feedback en reflectie zich ook vertalen in beter leren van de student.

\section{Literatuur}

1. Vermunt J. Docent van deze tijd: leren en laten leren. Rede uitgesproken aan de Universiteit van Utrecht. Utrecht: IVLOS; 2006.

2. Smith RA. Formative evaluation and the scholarship of teaching and learning. New Directions for Teaching and Learning 2001;88:51-62.

3. DeNisi AS, Kluger A. Feedback effectiveness: can 360-degree appraisals be improved? The Academy of Management Executive 2000;14(1):129-39. 
4. Tigelaar D, Dolmans D, Wolfhagen I. Kwaliteit van onderwijs en docentcompetenties. In: Hout $\mathrm{H}$ van, Dam G ten, Mirande M, Terlouw C, Willems $\mathrm{J}$, editors. Vernieuwing in het hoger onderwijs. Onderwijskundig handboek. Assen: Van Gorcum; 2006. p. 245-57.

5. Braskamp LA, Ory JC. Assessing faculty work. Enhancing individual and institutional performance. San Francisco: Jossey Bass; 1994.

6. Smither J, London M, Reilly RR. Does performance improve following multi source feedback? A theoretical model, meta-analysis, and review of empirical findings. Person Psychol 2005;8:33-66.

7. Sargeant J. Multi-source feedback for physician learning and change [dissertatie]. Maastricht: Universiteit Maastricht; 2006.

8. Tigelaar DEH, Dolmans DHJM, De Grave WS, Wolfhagen HAP, Vleuten van der CPM. Participants' opinions on the usefulness of a teaching portfolio. Med Educ 2006;40:371-8.

9. Dolmans D, Ginns P. A short questionnaire to evaluate the effectiveness of tutors in PBL: validity and reliability. Med Teach 2005;27(6):534-8.

10. Dolmans DHJM, Wolfhagen HAP, Snellen-Balendong HAM, Heus GCB de. Feedbacklijst tutoren als instrument voor professionalisering van docenten. Bulletin Medisch Onderwijs 1992;11(3/4):96-103.

11. Copeland HL, Hewson MG. Developing and testing an instrument to measure the effectiveness of clinical teaching in an academic medical centre. Acad Med 2000;75(2):161-6.

12. Dolmans DHJM, Wolfhagen HAP, Gerver WJ, Scherpbier AJJA. Providing physicians with feedback on how they supervise students during patient contacts. Med Teach 2004;26(5):409-14.

13. Litzelman DK, Stratos GA, Marriott DJ, Skeff KM. Factorial validation of a widely disseminated educational framework for evaluating clinical teachers. Acad Med 1998;73( 6):688-95.
14. Van der Hem-Stokroos HH, Van der Vleuten CPM, Daelmans HEM, Haarman HJTM, Scherpbier AJJA. Reliability of the clinical teaching effectiveness instrument. Med Educ 2005;39:904-10.

15. Marsh HW, Roche LA. Effects of grading leniency and low workload on students' evaluations of teaching: popular myths, bias, validity or innocent bystanders? J Educ Psychol 2000;92(1):202-28.

16. Seldin P. Changing practices in evaluating teaching. A practical guide to improved faculty performance and promotion/tenure decisions. Bolton, MA: Anker Publishing; 1999.

17. Davies H, Archer J. Multi source feedback: development and practical aspects. The Clinical Teacher 2005;2(2):77-81.

18. Tigelaar EH, Dolmans DHJM, Wolfhagen HAP, Van der Vleuten CPM. Quality issues in judging portfolios: implications for organizing teaching portfolio assessment procedures. Studies in Higher Education 2005;30(5):595-610.

De auteurs:

Dr. Diana H.J.M. Dolmans, drs. Renée E. Stalmeijer en dr. Ineke H.A.P. Wolfhagen zijn allen onderwijskundigen. Zij zijn betrokken bij de evaluatie van docenten aan de Faculteit der Geneeskunde van de Universiteit Maastricht en werkzaam bij de Capaciteitsgroep Onderwijsontwikkeling en -research.

Correspondentieadres:

Dr. Diana Dolmans, Universiteit Maastricht, Capaciteitsgroep O\&O, Postbus 616, 6200 MD Maastricht, tel.: 043-3885730,D.Dolmans@educ.unimaas.nl.

Belangenconflict: geen gemeld.

Financiële ondersteuning: geen gemeld.

\section{Summary}

It is generally assumed that teachers' professional development benefits from feedback. Important conditions for effective feedback are that it is specific, diagnostic, relevant and accompanied by suggestions for improvement. Preferably, feedback should not be in writing only, but teachers should receive guidance in interpreting feedback and the opportunity to talk about it. Increasingly use is being made of a variety of instruments and information sources for feedback. I can be part of a teaching portfolio, containing teachers' reflections on the included evidential materials as well as their personal objectives for professional development. (Dolmans DHJM, Stalmeijer RE, Wolfhagen HAP. Feedback to support teachers' professional development. Dutch Journal of Medical Education 2006;25(6):267-272.) 